\title{
Perioperative fatigue in patients with diffuse glioma
}

\author{
Stine Schei ${ }^{1} \mathbb{D} \cdot$ Ole Solheim $^{2,3} \cdot$ Asgeir Store Jakola ${ }^{2,4,5} \cdot$ Lisa Millgård Sagberg $^{1,3}$
}

Received: 25 October 2019 / Accepted: 16 January 2020 / Published online: 23 January 2020

(c) The Author(s) 2020

\begin{abstract}
Purpose Few studies have assessed fatigue in relation to glioma surgery. The purpose of this study was to explore the prevalence of pre- and postoperative high fatigue, perioperative changes, and factors associated with pre- and postoperative high fatigue in patients undergoing primary surgery for diffuse glioma.

Methods A total of 112 adult patients were prospectively included. Patient-reported fatigue was assessed before and one month after surgery using the cancer-specific European Organization for Research and Treatment of Cancer questionnaire fatigue subscale. The scores were dichotomized as high fatigue $(\geq 39)$ or low fatigue $(<39)$. A change in score of $\geq 10$ was considered as a clinically significant change. Factors associated with pre- and postoperative high fatigue were explored in multivariable regression analyses.

Results High fatigue was reported by $45 \%$ of the patients preoperatively and by $42 \%$ of the patients postoperatively. Female gender and low Karnofsky Performance Status (KPS) were associated with preoperative high fatigue, while postoperative complications, low KPS and low-grade histopathology were associated with postoperative high fatigue. In total 35/92 (38\%) patients reported a clinically significant improvement of fatigue scores after surgery, 36/92 (39\%) patients reported a clinically significant worsening of fatigue scores after surgery, and 21/92 (23\%) patients reported no clinically significant change in fatigue scores after surgery. Patients with low-grade gliomas more often reported low fatigue before surgery and high fatigue after surgery, while patients with high-grade gliomas more often reported high fatigue before surgery and low fatigue after surgery.

Conclusions Our findings indicate that fatigue is a common symptom in patients with diffuse glioma, both pre- and postoperatively. Perioperative changes were frequently seen. This is important knowledge when informing patients before and after surgery.
\end{abstract}

Keywords Brain neoplasms $\cdot$ Glioma $\cdot$ Fatigue $\cdot$ Surgery $\cdot$ Perioperative period

Electronic supplementary material The online version of this article (https://doi.org/10.1007/s11060-020-03403-0) contains supplementary material, which is available to authorized users.

Stine Schei

stine.schei@ntnu.no

1 Department of Public Health and Nursing, Norwegian University of Science and Technology, Trondheim, Norway

2 Department of Neuromedicine and Movement Science, Norwegian University of Science and Technology, Trondheim, Norway

3 Department of Neurosurgery, St. Olavs Hospital, Trondheim, Norway

4 Department of Neurosurgery, Sahlgrenska University Hospital, Gothenburg, Sweden

5 Institute of Neuroscience and Physiology, University of Gothenburg, Sahlgrenska Academy, Gothenburg, Sweden

\section{Introduction}

Diffuse gliomas are the most common types of primary brain tumors [1]. Due to their infiltrative growth pattern they cannot be cured [2], and the median survival is up to approximately 15 years for patients with low-grade glioma (LGG) [3] and 10-12 months for patients with high-grade glioma (HGG) $[4,5]$. The incurable nature of diffuse gliomas thus makes preservation of quality of life a paramount factor to consider in treatment decision making. Even though extensive surgical resections may prolong survival in both LGG and HGG [6-8], there is a significant risk of adverse effects such as postoperative complications and acquired neurological deficits. However, intact neurological functions after surgery do not necessarily guarantee preservation of quality of life as more subtle and subjective symptoms may be 
undetected. In fact, cancer patients indicate fatigue as one of the most troublesome symptom related to cancer and its treatment [9], and the symptom is also common in glioma patients with an estimated prevalence of 36-82\% [10-14].

Cancer-related fatigue is complex and can be influenced by treatment-related factors, and physical and emotional consequences of the diagnosis [15]. The underlying biological mechanisms of fatigue are poorly understood, but there is growing evidence that elevated levels of proinflammatory cytokines plays an important role, at least in extracranial cancers [16]. Proinflammatory cytokines are either released by immune cells following infection, by the tumor itself, or by tissue damage from surgery and/or adjuvant treatment [15]. In glioma patients, fatigue has mainly been studied in relation to oncological treatment [13, 17-20], and studies have found that fatigue is a prominent symptom already prior to oncological treatment $[13,20]$. Fatigue is also found to have a negative impact on glioma patients' health-related quality of life (HRQOL) [11, 14, 21], and to be a negative prognostic factor for survival in patients with HGG [19]. However, there is limited knowledge about fatigue in the perioperative neurosurgical setting, and there is a lack of longitudinal studies with fatigue as the primary outcome in this patient group.

We hypothesized that fatigue is a common symptom in the perioperative course and that the prevalence of fatigue may increase after surgery. The aims of this prospective study were therefore (1) to explore the prevalence of pre- and postoperative high fatigue in patients undergoing primary surgery for diffuse glioma, (2) to investigate perioperative changes, and (3) to explore patient- and treatment-related factors associated with pre- and postoperative high fatigue.

\section{Methods}

\section{Study design and population}

All patients aged $\geq 18$ years that underwent primary surgical resection under general anesthesia for a grade II-IV glioma at the neurosurgical department at St. Olavs Hospital (Trondheim, Norway) from September 2011 through November 2015 were assessed for inclusion. This department serves a defined geographic catchment region with a population of approximately 720,000 , ensuring a populationbased referral. In total 112 patients were included in the study and filled out the European Organization for Cancer Treatment (EORTC) QLQ-C30 questionnaire at baseline. A flow chart of the inclusion process is presented in Supplementary Fig. 1. There was no significant difference in age $(p=0.756)$ nor Karnofsky Performance Status (KPS) $(p=0.095)$ between included patients and those without informed consent. Twenty patients (18\%) were lost to follow up at 1 month, which left 92 patients with complete preand postoperative data. All tumors were histopathologically verified by a neuropathologist according to the 2007 World Health Organization-classification [22].

\section{The EORTC QLQ-C30 questionnaire}

EORTC QLQ-C30 (version 3.0) is a validated and widely used questionnaire for HRQOL in cancer patients [23]. It contains 30 questions with five functioning domains, a global health status, six single-item scales, and three symptom scales. Fatigue is included as an unidimensional subscale and comprises three items assessing the physical domain of symptom intensity during the past week: "Did you need to rest?", "Have you felt weak?", and "Were you tired?". Each question is answered on a four-point ordinal scale, where 1 is described as "not at all", 2 as "a little", 3 as "quite a bit", and 4 as "very much". The fatigue subscale has a high level of internal consistency, as determined with a Cronbach's alpha of 0.88 .

\section{Data collection and variables}

The patients completed the Norwegian translated EORTCquestionnaire at admission 1-3 days before surgery. Followup assessments were performed by structured telephone interviews by a study nurse approximately 30 days postoperatively (median 31 days; range 23-63, mean 33 days \pm 6.9 ). Assistance from proxies was used when the patients were too ill to answer, had considerable cognitive impairments or severe communication problems (5\% of all follow-up interviews).

Demographic and clinical data were retrospectively obtained from electronic medical records (six regional hospitals and one university hospital). Preoperative symptoms were defined as new and/or increased tumor-related symptoms that was recorded in the medical journal prior to surgery. Only new or worsened language and/or motor deficits at discharge confirmed as persistent by patients at 30 days were included in the postoperative analyses. Charlson Comorbidity Index (CCI) was used to classify comorbidity [24], and complications during the first 30 postoperative days were graded as suggested by Landriel Ibañez et al. [25]. KPS was scored by the operating neurosurgeon just before surgery, while the postoperative scores were scored by a trained study nurse based on information from the telephone interviews. In one patient preoperative KPS was missing, and a retrospective estimation based on notes from the medical record was done to classify the patient as functionally dependent $(\mathrm{KPS}<70)$ or functionally independent (KPS $\geq 70$ ). Pre- and postoperative tumor volumes and tumor locations were obtained from pre- and postoperative magnetic resonance imaging 
(MRI) scans. The tumor volumes were estimated by a neurosurgeon by applying the volume formula $V=4 \pi \times r^{3} / 3$, based on perpendicular tumor diameters. The volume of pathological contrast-enhancement and necrotic tissue within the contrast-enhancing borders were used in contrast-enhancing tumors, while the entire volume as seen in T2/FLAIR sequences was used in tumors without contrast-enhancement.

\section{Statistical analyses}

In accordance with the EORTC scoring manual, the fatigue subscale were transformed to a 0-100 scale with higher scores indicating more severe fatigue [26]. To identify only patients with clinically significant and severe fatigue, the fatigue scores were further grouped as "high fatigue" $(\geq 39)$ or "low fatigue" $(<39)$ as recommended by Giesinger et al. [27].

All statistical analyses were performed using SPSS version 25.0. Statistical significance was defined as $p<0.05$. The correlation between fatigue and categorical factors was explored using Pearson's $\chi^{2}$ tests. Fisher exact test was used when the expected number of cells was $\leq 5$. Q-Q plots and Shapiro-Wilk tests were used to test for normal distribution for continuous variables. Means are presented if data was normally distributed, while medians are presented if data was skewed. Student's sample $t$ test or Mann-Whitney U tests were carried out to compare continuous variables depending on whether data were normally distributed or skewed. Binary logistic regression analyses were performed, and only univariables with a statistical trend $(\mathrm{p}<0.1)$ were included in the multivariable models. The potential collinearity between variables was assessed with correlation coefficients, tolerance values, and the variance inflation factor (VIF). The Hosmer-Lemeshow goodness-of-fit test was used to determine goodness of fit of the logistic regression model, and the Nagelkerke R square value was used to assess how much variation in the dependent variable that could be explained by the model. Perioperative changes in fatigue were examined in a cross-table, and possible associated factors at group level. High fatigue before surgery and low fatigue after surgery was defined as a score of $\geq 39$ preoperatively, and $<39$ at postoperative follow-up. While low fatigue before surgery and high fatigue after surgery was defined as a score of $<39$ preoperatively, and a score of $\geq 39$ postoperatively. To assess clinically relevant change in fatigue score, the previously published minimal clinically important difference score of \pm 10 for patients with brain cancer was applied [28].

\section{Missing data}

In one patient, one fatigue-item was missing at baseline. This item was therefore imputed according to EORTC scoring manual by assuming that the missing item value was equal to the average of those other two items scored by the patient [26].

\section{Results}

\section{Preoperative fatigue and possible associated factors}

In Table 1, preoperative data for patients with high and low levels of fatigue symptoms are compared. As seen, 50/112 patients $(45 \%)$ reported high fatigue the last week before surgery, and women reported high fatigue more frequently than men $(66 \%$ vs. $34 \%, p=0.001)$. Patients with functional dependency reported more high fatigue compared to those with functional independency ( $79 \%$ vs. $40 \%, p=0.006$ ). Also, preoperative high fatigue was more common in patients with nausea/vomiting ( $89 \%$ vs. $11 \%, \mathrm{p}=0.010$ ), motor deficits ( $73 \%$ vs. $27 \%, \mathrm{p}=0.016$ ), and dizziness/balance/coordination problems (66\% vs. $34 \%, p=0.009)$. In contrast, high fatigue was less common in patients with seizures ( $30 \%$ vs. $70 \%, \mathrm{p}=0.010)$.

Possible factors associated with preoperative high fatigue were further explored in a multivariable logistic regression analysis (Table 2). All preoperative factors in Table 1 were first tested as univariables. Of these, gender, KPS, and symptoms such as seizures, motor deficits, dizziness/balance/coordination problems and headache showed a statistical trend $(\mathrm{p}<0.1)$ and were included in the multivariable model. There was no evidence of multicollinearity between the independent variables (correlation $<0.7$, tolerance value $>0.1$ and VIF < 10). One patient was an outlier and therefore excluded from the analyses and one patient missing exact KPS. As seen, female gender and low KPS were the only significantly associated factors for preoperative high fatigue in the multivariable model. Females had 3.3 times higher odds for preoperative high fatigue than men, and higher KPS reduced odds for high fatigue. The Hosmer-Lemeshow test was not significant $(\mathrm{p}=0.085)$, implying that the regression model was a good fit. The model explained $30.4 \%$ of the variance in development of fatigue and correctly classified $76.4 \%$ cases.

\section{Postoperative fatigue and possible associated factors}

In Table 3, postoperative data for patients with high and low levels of fatigue symptoms are compared. As seen, 39/92 $(42 \%)$ reported high fatigue one month after surgery, and 
Table 1 Baseline data, prevalence of preoperative fatigue, and possible associated factors, $n=112$
Characteristics

Age (years), median (range)

Gender

Female

Male

Histopathology

Diffuse low-grade glioma

High-grade glioma

Location

Frontal

Temporal

Parietal

Occipital

Cerebellum/brainstem

Basal ganglia ${ }^{a}$

Multiple lobes

Lateralization

Right

Left

Bilateral/midline

Preoperative KPS

$\geq 70$

$<70$

Preoperative symptoms ${ }^{\mathrm{c}}$

Headache

Seizures

Cognitive change

Nausea/vomiting

Dizziness/balance/coordination problems

Visual disturbance

Language problems

Cranial nerve deficits

Motor deficits

$\mathrm{CCI}>1^{\mathrm{d}}$

Preoperative corticosteroids

Yes

No

Preoperative antiepileptic drugs

Yes

No

Preoperative tumor volume $\mathrm{cm}^{3}$, median (range)

Bold values indicate $\mathrm{p}<0.05$

${ }^{a}$ Basal ganglia/thalamus/corpus callosum/insula

${ }^{b}$ Karnofsky Performance Status score

${ }^{\mathrm{c}}$ Some patients had multiple symptoms

${ }^{\mathrm{d}}$ Charlson Comorbidity Index
High fatigue $(\mathrm{N}=50) \quad$ Low fatigue $(\mathrm{N}=62) \quad p$ value $\mathrm{n} / \mathrm{N}(\%)$

$\begin{array}{lll}56(18-80) & 62(23-80) & 0.482 \\ & & \mathbf{0 . 0 0 1}\end{array}$

25/38 (66)

$13 / 38(34)$

25/74 (34)

49/74 (66)

$13 / 31(42)$

0.721

$37 / 81(46)$

$18 / 31(58)$

$44 / 81(54)$

$15 / 43(35)$

$28 / 43(65)$

0.101

$11 / 26(42)$

$15 / 26(58)$

0.785

$3 / 3$ (100)

$0 / 3(0)$

0.086

$0 / 0(0)$

$0 / 0(0)$

N/A

2/2 (100)

$0 / 2(0)$

0.197

$1 / 5$ (20)

18/33 (55)

$4 / 5$ (80)

0.378

$15 / 33$ (45)

0.173

26/55 (47)

23/52 (44)

29/55 (53)

0.582

29/52 (56)

0.935

$1 / 5$ (20)

4/5 (80)

0.378

39/98 (40)

$59 / 98$ (60)

3/14 (21)

23/41 (56)

13/44 (30)

18/41 (44)

0.064

19/36 (53)

$31 / 44$ (70)

0.010

8/9 (89)

17/36 (47)

0.233

$19 / 29$ (66)

1/9 (11)

10/29 (34)

0.010

4/6 (67)

2/6 (33)

0.009

$13 / 28$ (46)

$15 / 28(54)$

0.405

$9 / 14(64)$

$5 / 14(36)$

0.826

$11 / 15(73)$

$4 / 15$ (27)

0.114

$2 / 5$ (40)

$3 / 5(60)$

0.016

1.0

$32 / 66(48)$

$34 / 66(52)$

18/46 (39)

28/46 (61)

0.327

0.111

$13 / 38(34) \quad 25 / 38(66)$

$37 / 74$ (50)

$37 / 74$ (50)

20.39 (1.01-94.78) patients with postoperative high fatigue were significantly younger than those with low fatigue (median age 54 years [range 20-76] vs. 62 years [range 18-80], $\mathrm{p}=0.046$ ).
Patients with LGG more often reported high fatigue than those with HGG (61\% vs. $34 \%, \mathrm{p}=0.019)$. Also, patients who experienced moderate and/or severe complications 
Table 2 Possible associated factors for high fatigue at baseline $(n=110)$ and at postoperative follow-up $(n=92)$

\begin{tabular}{|c|c|c|c|c|}
\hline \multirow[t]{2}{*}{ Variables in the binary regression model } & \multicolumn{2}{|c|}{ Univariable analyses } & \multicolumn{2}{|c|}{ Multivariable analyses } \\
\hline & OR $(95 \% \mathrm{CI})$ & $p$ value & OR $(95 \% \mathrm{CI})$ & $p$ value \\
\hline \multicolumn{5}{|c|}{ Possible associated factors for high fatigue at baseline, $\mathrm{n}=110^{\mathrm{a}}$} \\
\hline Female & $3.69(1.61-8.44)$ & 0.002 & $3.28(1.29-8.31)$ & 0.012 \\
\hline Preoperative KPS & $0.94(0.91-0.97)$ & 0.001 & $0.95(0.92-0.99)$ & 0.017 \\
\hline Seizure & $0.34(0.15-0.76)$ & 0.009 & $0.69(0.25-1.91)$ & 0.485 \\
\hline Motor deficits & $4.01(1.19-13.54)$ & 0.025 & $1.96(0.47-8.11)$ & 0.350 \\
\hline Dizziness/balance/coordination problems & $3.12(1.28-7.58)$ & 0.012 & $1.60(0.56-4.56)$ & 0.379 \\
\hline Headache & $2.20(1.00-4.85)$ & 0.050 & $1.46(0.57-3.72)$ & 0.428 \\
\hline \multicolumn{5}{|c|}{ Possible associated factors for high fatigue at postoperative follow-up, $\mathrm{n}=92$} \\
\hline Age & $0.97(0.94-0.99)$ & 0.040 & $0.97(0.93-1.01)$ & 0.142 \\
\hline Low-grade glioma & $2.95(1.18-7.38)$ & 0.021 & $4.20(1.11-15.88)$ & 0.034 \\
\hline Moderate and/or severe complications ${ }^{\mathrm{b}}$ & $4.18(1.40-16.55)$ & 0.013 & $7.11(1.65-30.55)$ & 0.008 \\
\hline Postoperative KPS & $0.94(0.89-0.98)$ & 0.006 & $0.91(0.86-0.96)$ & 0.001 \\
\hline
\end{tabular}

Bold values indicate $\mathrm{p}<0.05$

$O R$ odds ratio, $C I$ confidence interval, KPS Karnofsky Performance Status score

${ }^{a}$ One patient excluded due to outlier and one patient missing exact KPS

${ }^{\mathrm{b}}$ Landriel grade II-III
(Landriel grade II-III) more often reported postoperative high fatigue ( $73 \%$ vs. $27 \%, \mathrm{p}=0.008)$.

To identify factors possibly associated with postoperative high fatigue, all factors in Table 3 were first tested as univariables. Of these, age, histology, KPS and postoperative complications were further included in the multivariable model $(\mathrm{p}<0.1)$ (Table 2). There was no evidence of multicollinearity between the independent variables. In the multivariable analyses, low-grade histopathology, low KPS and moderate and/or severe complications were statistically significantly associated with postoperative high fatigue. The multivariable regression model was a good model of fit $(p=0.372)$. The model explained $37.4 \%$ of the variance in fatigue and correctly classified $76.1 \%$ of cases.

\section{Change in fatigue and possible associated factors}

In all 112 patients, the median preoperative fatigue score was 33.3 (range $0-100$ ) and in the 92 patients with follow up data, the median postoperative EORTC fatigue score was 33.3 (range $0-100$ ), $p=0.511$. In total 35/92 (38\%) patients reported a clinically significant improvement of fatigue scores after surgery, 36/92 (39\%) patients reported a clinically significant worsening of fatigue scores after surgery, and 21/92 (23\%) patients reported no clinically significant change in fatigue scores after surgery. Both patients with LGG and HGG had a median fatigue score of 33.3 before surgery, while patients with LGG had higher median fatigue scores after surgery (median $=44.4,95 \%$ CI $30.1-54.0$ vs. median $=33.3$, 95\% CI 29.9-41.6) (Supplementary Fig. 2).
Dichotomized dynamics of change in fatigue from baseline to 1 month after surgery are shown in Table 4 . Of 92 patients, $15(16 \%)$ reported low fatigue before surgery and high fatigue after surgery, 62 (68\%) reported no change, and $15(16 \%)$ reported high fatigue before surgery and low fatigue after surgery.

Table 5 shows the frequency of fatigue change at group level and possible associated factors. As seen in this hypothesis-generating table, low fatigue before surgery and high fatigue after surgery was more common in patients with LGG compared to patients with HGG (25\% vs. $12 \%)$. Also, patients with LGG less often reported high fatigue before surgery and low fatigue after surgery compared to patients with HGG (3\% vs. 22\%). Patients reporting perioperative change in fatigue seem to have larger preoperative tumor volumes compared to those without change. Of those with moderate and/or severe complications, $40 \%$ reported low fatigue before and high fatigue after surgery. Low fatigue both before and after surgery was more common among men ( $48 \%$ vs. $27 \%$ ) and in patients with higher preoperative functional levels (KPS $\geq 70)(45 \%$ vs. $11 \%)$.

\section{Discussion}

This prospective study explored fatigue in relation to primary surgery in patients with diffuse gliomas. Our findings indicate that fatigue is a prominent symptom in this patient group, as almost half of the patients experienced high levels of fatigue both before and after surgery. Female gender and low KPS were factors associated with preoperative high fatigue, while moderate and/or severe complications, 
Table 3 Postoperative data, prevalence of postoperative fatigue, and possible associated factors, $n=92$

\begin{tabular}{|c|c|c|c|}
\hline Characteristics & $\begin{array}{l}\text { High fatigue }(\mathrm{N}=39) \text {, } \\
\mathrm{n} / \mathrm{N}(\%)\end{array}$ & $\begin{array}{l}\text { Low fatigue }(\mathrm{N}=53) \text {, } \\
\mathrm{n} / \mathrm{N}(\%)\end{array}$ & $p$ value \\
\hline Age (years), median (range) & $54(20-76)$ & $62(18-80)$ & 0.046 \\
\hline Gender & & & 0.304 \\
\hline Female & $15 / 30(50)$ & $15 / 30(50)$ & \\
\hline Male & $24 / 62(39)$ & $38 / 62(61)$ & \\
\hline Histopathology & & & 0.019 \\
\hline Diffuse low-grade glioma & $17 / 28(61)$ & $11 / 28(39)$ & \\
\hline High-grade glioma & $22 / 64(34)$ & $42 / 64(66)$ & \\
\hline \multicolumn{4}{|l|}{ Location } \\
\hline Frontal & $14 / 36(39)$ & $22 / 36(61)$ & 0.586 \\
\hline Temporal & $10 / 23(44)$ & $13 / 23(56)$ & 0.903 \\
\hline Parietal & $2 / 2(100)$ & $0 / 2(0)$ & 0.177 \\
\hline Occipital & $0 / 0(0)$ & $0 / 0(0)$ & N/A \\
\hline Cerebellum/brainstem & $1 / 1(100)$ & $0 / 1(0)$ & 0.424 \\
\hline Basal ganglia & $4 / 5(80)$ & $1 / 5(20)$ & 0.159 \\
\hline Multiple lobes & $8 / 25(32)$ & $17 / 25(68)$ & 0.218 \\
\hline \multicolumn{4}{|l|}{ Lateralization } \\
\hline Right & $18 / 44(59)$ & $26 / 44(41)$ & 0.783 \\
\hline Left & $21 / 45(47)$ & $24 / 45(53)$ & 0.417 \\
\hline Bilateral & $0 / 3(0)$ & $3 / 3(100)$ & 0.259 \\
\hline Postoperative KPS $^{\mathrm{a}}$ & & & 0.969 \\
\hline$\geq 70$ & $33 / 78(42)$ & $45 / 78(58)$ & \\
\hline$<70$ & $6 / 14(43)$ & $8 / 14(57)$ & \\
\hline Moderate and/or severe complications ${ }^{\mathrm{b}}$ & $11 / 15(73)$ & $4 / 15(27)$ & 0.008 \\
\hline New neurological deficits ${ }^{c}$ & $6 / 13(46)$ & $7 / 13(54)$ & 0.767 \\
\hline $\mathrm{CCI}>1^{\mathrm{d}}$ & $2 / 4(50)$ & $2 / 4(50)$ & 1.0 \\
\hline Corticosteroids at follow up & & & 0.367 \\
\hline Yes & $7 / 13(54)$ & $6 / 13(46)$ & \\
\hline No & $32 / 79(40)$ & $47 / 79(60)$ & \\
\hline Antiepileptic drugs at follow up & & & 0.768 \\
\hline Yes & $15 / 37$ & $22 / 37$ & \\
\hline No & $24 / 55$ & $31 / 55$ & \\
\hline Extent of resection $(\%)$, median $(\text { range })^{\mathrm{e}}$ & $93.5(31.8-100)$ & $94.9(24.0-100)$ & 0.302 \\
\hline \multicolumn{4}{|l|}{ Adjuvant treatment $<$ follow up } \\
\hline Chemotherapy ${ }^{\mathrm{f}}$ & 19/52 (36) & $33 / 52(64)$ & 0.195 \\
\hline Radiotherapy & $18 / 51(35)$ & $33 / 51(65)$ & 0.124 \\
\hline
\end{tabular}

Bold values indicate $\mathrm{p}<0.05$

${ }^{a}$ Karnofsky Performance Status score

${ }^{\mathrm{b}}$ Landriel grade II-III

${ }^{\mathrm{c}}$ Motor and/or language deficits at discharge confirmed as persistent by patients at 30 days

${ }^{\mathrm{d}}$ Charlson Comorbidity Index

${ }^{\mathrm{e}} \mathrm{N}=89$ due to 3 missing MRI

${ }^{\mathrm{f}}$ Only temozolomide (no patients had received procarbazine, lomustine and vincristine) low-grade histology and low KPS were associated with high fatigue one month after surgery. At group level, just as many reported low fatigue preoperatively and high fatigue postoperatively, as high fatigue preoperatively and low fatigue postoperatively. Patients with LGG more often reported low fatigue before surgery and high fatigue after surgery, while patients with HGG more often reported high fatigue before surgery and low fatigue after surgery. Patients with large tumors more often reported perioperative change compared to patients with smaller tumors.

In the general Norwegian population, the median EORTC fatigue score is 28.8 and thereby lower than the pre- and 
Table 4 Change in fatigue from baseline to 1 month postoperatively

\begin{tabular}{llll}
\hline & \multicolumn{3}{l}{ Postoperative, $\mathrm{n}(\%)$} \\
\cline { 2 - 4 } & High fatigue & Low fatigue & Total \\
\hline Preoperative, $\mathrm{n}(\%)$ & & $15(16)$ & $39(42)$ \\
High fatigue & $24(26)$ & $38(42)$ & $53(58)$ \\
Low fatigue & $15(16)$ & $53(58)$ & $92(100)$ \\
Total & $39(42)$ & & \\
\hline
\end{tabular}

postoperative median scores found in our glioma population [29]. In the single prior study with preoperative data that can be compared with ours the fatigue prevalence was almost twice as high [14]. The difference in patient selection, study design, assessment time point, and definition of fatigue may explain why the prevalence differed. The postoperative prevalence found in our study is comparable with a previous study of glioblastoma patients, where $48 \%$ reported fatigue at postsurgical baseline [13]. However, the lack of consensus in assessment of fatigue with respect to different questionnaires, cut-off scores and assessment time points hamper meaningful comparisons between studies. Also, most previous studies on fatigue in glioma patients are cross-sectional with strict inclusion criteria, where patients with KPS $<70$ and cognitive impairments are often excluded [10-12, 14, $17,18,20,30,31]$.

We found female gender to be associated with high fatigue before, but not after surgery. As suggested by others, women may be more aware of, or more willing, to report their symptoms compared to men [32]. The finding may also be explained by that women, in general, experience stronger emotional reactions to illness than men [33]. Admittedly, our sample included twice as many men than women, which may have affected these results. The reported findings on the impact of gender in relation to fatigue varies in the literature. In glioma patients, Cheng et al. found no association between female gender and fatigue prior to surgery [14], while another study found female gender to be associated with fatigue in glioblastoma patients after surgery [13]. Further, a relationship between fatigue and female gender has been found both in patients with general cancer [34] and in the general population [29].

Poor functional status is a well-known negative prognostic factor for survival in patients with diffuse glioma [35, 36], and we found patients with low pre- and postoperative KPS also to have a slightly increased odds of high levels of fatigue. In accordance with our findings, a relationship between low KPS and preoperative high fatigue is found in a previous study as well [14], while another study found no

Table 5 Change in fatigue and possible associated factors, $n=92$

\begin{tabular}{|c|c|c|c|c|}
\hline Characteristics & $\begin{array}{l}\text { Low fatigue both } \\
\text { before and after } \\
\text { surgery } \\
(\mathrm{N}=38) \\
\mathrm{n} / \mathrm{N}(\%)\end{array}$ & $\begin{array}{l}\text { High Fatigue both } \\
\text { before and after } \\
\text { surgery } \\
(\mathrm{N}=24) \\
\mathrm{n} / \mathrm{N}(\%)\end{array}$ & $\begin{array}{l}\text { High fatigue before and } \\
\text { low fatigue after surgery } \\
(\mathrm{N}=15) \\
\mathrm{n} / \mathrm{N}(\%)\end{array}$ & $\begin{array}{l}\text { Low fatigue before } \\
\text { and high fatigue after } \\
\text { surgery } \\
(\mathrm{N}=15) \\
\mathrm{n} / \mathrm{N}(\%)\end{array}$ \\
\hline Age (years), median (range) & $62(34-79)$ & $53(20-76)$ & $55(18-80)$ & $61(23-74)$ \\
\hline \multicolumn{5}{|l|}{ Gender } \\
\hline Female & $8 / 30(27)$ & $11 / 30(37)$ & $7 / 30(23)$ & $4 / 30(13)$ \\
\hline Male & $30 / 62(48)$ & $13 / 62(21)$ & $8 / 62(13)$ & $11 / 62(18)$ \\
\hline \multicolumn{5}{|l|}{ Histopathology } \\
\hline Diffuse low-grade glioma & $10 / 28(36)$ & $10 / 28(36)$ & $1 / 28(3)$ & $7 / 28(25)$ \\
\hline High-grade glioma & $28 / 64(44)$ & $14 / 64(22)$ & $14 / 64(22)$ & $8 / 64(12)$ \\
\hline \multicolumn{5}{|l|}{ Preoperative KPS ${ }^{\mathrm{b}}$} \\
\hline$\geq 70$ & $37 / 82(45)$ & $20 / 82(24)$ & $12 / 82(15)$ & $13 / 82(16)$ \\
\hline$<70$ & $1 / 9(11)$ & $3 / 9(33)$ & $3 / 9(33)$ & $2 / 9(22)$ \\
\hline \multicolumn{5}{|l|}{ Postoperative $\mathrm{KPS}^{\mathrm{b}}$} \\
\hline$\geq 70$ & $34 / 78(44)$ & $21 / 78(27)$ & $11 / 78(14)$ & $12 / 78(15)$ \\
\hline$<70$ & 4/14 (29) & $3 / 14(21)$ & 4/14 (29) & $3 / 14(21)$ \\
\hline $\begin{array}{l}\text { Preoperative tumor volume } \mathrm{cm}^{3} \text {, median } \\
\text { (range) }\end{array}$ & $16.85(1.91-86.19)$ & $19.72(0.51-103.26)$ & $30.38(1.50-107.89)$ & $29.97(1.01-94.78)$ \\
\hline Extent of resection (\%), median (range) & $95.1(36.1-100)$ & $92.7(45.4-100)$ & $94.8(24.0-100)$ & $94.7(31.8-100)$ \\
\hline Moderate and/or severe complications ${ }^{\mathrm{c}}$ & $4 / 15(27)$ & $5 / 15(33)$ & $0 / 15(0)$ & $6 / 15(40)$ \\
\hline
\end{tabular}

${ }^{a}$ All of these patients had clinical important change

${ }^{\mathrm{b}}$ Karnofsky Performance Status score

${ }^{\mathrm{c}}$ Landriel grade II-III 
relationship between KPS and fatigue at postsurgical baseline [13].

Low-grade histology was another independent factor for postoperative high fatigue, and patients with LGG had higher median postoperative fatigue scores, whereas the HGG group had stable median fatigue scores one month after surgery. This may seem surprising considering the poorer prognosis and often lower functional status in HGG patients [37]. Since most of the patients who were lost to follow up had HGG, selection bias may be an issue. Another explanation could perhaps be that patients with LGG are often younger and less symptomatic prior to surgery and may have higher expectations and obligations to carry on with the same activities, both at work and in their social life as before surgery, and thus experience a larger difference between their present and previous situation.

Of note, preoperative high fatigue appeared to be less common in patients with seizures, although not significant in the multivariable analyses. Seizures is a common symptom, especially in patients with LGG and in cases where the tumor is located in the frontal, temporal and parietal lobes [38]. Thus, this finding may perhaps have been confounded by the higher frequency of frontal tumors and low-grade histology in the "low fatigue" group. Preventing surgical complications are of always of importance and moderate and/or severe postoperative complications were found to be associated with postoperative fatigue. However, this finding was based on relatively few patients, and some of them also had several complications which makes further interpretation difficult.

Perioperative changes in fatigue were frequently seen on an individual level. Postoperative reduced mass effect or reduced peritumoral edema may explain why some patients experienced high levels of fatigue before surgery and low levels of fatigue after surgery. While inflammatory response due to tissue irritation/damage following surgery may explain why some experienced low fatigue before surgery and high fatigue after surgery. The tumor itself is also known to elicit inflammation. Patients with a perioperative change had seemingly larger preoperative tumor volumes. However, a previous cross-sectional study found no relationship between tumor size and fatigue in primary brain tumor patients [31], and no association between fatigue and extent of resection in glioblastoma patients at postsurgical baseline has been found [13].

The high pre- and postoperative prevalence and the perioperative change in fatigue may also be attributed to psychological and emotional responses to the cancer diagnosis and surgery. Some patients may be anxious and/or depressed after being diagnosed and treated for a life-threatening disease, while others may experience some relief after successful surgery.
To our knowledge, this is the first study to explore the implications of surgery on fatigue in patients with diffuse glioma, and the unselected study population increase the generalizability of our findings. The fatigue assessment was prospective and standardized using a validated cancer-specific questionnaire. Admittedly, when measuring fatigue as a defined end-point, it may seem more reasonable to use a fatigue-specific questionnaire that cover more than physical dimensions of fatigue [39]. However, challenges regarding data collection and high drop-out rates are known problems in longitudinal studies of glioma patients [40], and complicated forms may introduce selection bias. Thus, since the present study was part of a larger project already using the EORTC QLQ-C30 questionnaire, the fatigue subscale was used to ensure compliance and reduce the burden on patients. Other limitations that should be taken into account when interpreting the results are that our sample included almost twice as many men as women, and that psychosocial factors were not included in the analyses.

There is no ideal time point for assessing fatigue after surgery. The symptom tends to fluctuate over the course of the disease, and inappropriate timing of assessment can therefore result in failure to capture the true implications of surgery [41]. In the early postoperative period, it is more likely that fatigue can be affected by potential reversing contributory factors, such as analgesic, postoperative pain and transient postoperative complications. However, the symptom may also be a side effect of early initiated adjuvant treatment $[42,43]$. The clinical experience is that many patients operated for intracranial tumors report fatigue that gradually weans over several months. Thus, a later postoperative assessments than at one month may seem more appropriate. However, in rapid progressive diseases like HGG too late assessments may reflect disease progression more than treatment, and in patients with stable disease too late assessments may be affected by response shifts as patients adapt to their new situation over time [44].

Knowledge about fatigue in the surgical setting may raise awareness among clinicians that fatigue is a prominent symptom in the perioperative setting. This may be important knowledge when informing patients about what to expect after surgery. Patients with primary brain tumors have expressed a need for more preparatory information about fatigue [21], and described uncertainty about symptoms and how they could cope with the changes [45]. In addition, our findings may provide foundation for further research. For example, the symptom is not much explored in LGG patients after undergoing repeated resections and adjuvant interventions [3]. 


\section{Conclusions}

In this prospective study, we found fatigue to be a common symptom in patients with primary diffuse glioma, both before and after surgery. Female gender and low KPS were associated with high preoperative fatigue, and postoperative moderate and/or severe complications, low KPS and low-grade histopathology were associated with more postoperative fatigue. Perioperative change in fatigue was frequently seen. Since fatigue is likely to affect quality of life in glioma patients, knowledge of the symptom in the perioperative course is important when informing patients before and after surgery.

Acknowledgements Open Access funding provided by NTNU Norwegian University of Science and Technology (incl St. Olavs Hospital - Trondheim University Hospital). We would like to thank Camilla Brattbakk, Linda Nordtvedt and Even Hovig Fyllingen for assisting in data collection, and Øyvind Salvesen for valuable statistical advice.

Author contributions Conception and design: LMS, OS. Acquisition of data: LMS, OS, ASJ. Analysis and interpretation of data: SS, LMS, OS. Drafting the article: SS, LMS, OS. Critically revising the article: all authors. Reviewed submitted version of manuscript: all authors. Approved the final version of the manuscript on behalf of all authors: SS. Statistical analysis: SS, LMS. Study supervision: LMS, OS.

Data availability The datasets generated during and/or analysed during the current study are not publicly available due to privacy concerns but are available from the corresponding author on reasonable request.

\section{Compliance with ethical standards}

Conflict of interest The authors declare that they have no conflict of interest.

Ethical approval All procedures performed in studies involving human participants were in accordance with the ethical standards of the regional research committee (approved by the Regional Committee for Medical Research in Central Norway as part of a larger project, REC no. 2011/974), and with the 1964 Helsinki Declaration and its later amendments or comparable ethical standards.

Informed consent Informed consent was obtained from all individual participants included in the study.

Open Access This article is licensed under a Creative Commons Attribution 4.0 International License, which permits use, sharing, adaptation, distribution and reproduction in any medium or format, as long as you give appropriate credit to the original author(s) and the source, provide a link to the Creative Commons licence, and indicate if changes were made. The images or other third party material in this article are included in the article's Creative Commons licence, unless indicated otherwise in a credit line to the material. If material is not included in the article's Creative Commons licence and your intended use is not permitted by statutory regulation or exceeds the permitted use, you will need to obtain permission directly from the copyright holder. To view a copy of this licence, visit http://creativecommons.org/licenses/by/4.0/.

\section{References}

1. Ostrom QT, Gittleman H, Liao P, Vecchione-Koval T, Wolinsky Y, Kruchko C, Barnholtz-Sloan JS (2017) CBTRUS statistical report: primary brain and other central nervous system tumors diagnosed in the United States in 2010-2014. Neuro Oncol 19:v1v88. https://doi.org/10.1093/neuonc/nox158

2. Wen PY, Kesari S (2008) Malignant gliomas in adults. N Engl J Med 359:492-507. https://doi.org/10.1056/NEJMra0708126

3. Jakola A, Skjulsvik A, Myrmel K, Sjåvik K, Unsgård G, Torp S, Aaberg K, Berg T, Dai H, Johnsen K (2017) Surgical resection versus watchful waiting in low-grade gliomas. Ann Oncol 28:1942-1948. https://doi.org/10.1093/annonc/mdx230

4. Gramatzki D, Dehler S, Rushing EJ, Zaugg K, Hofer S, Yonekawa Y, Bertalanffy H, Valavanis A, Korol D, Rohrmann S, Pless M, Oberle J, Roth P, Ohgaki H, Weller M (2016) Glioblastoma in the Canton of Zurich, Switzerland revisited: 2005 to 2009. Cancer 122:2206-2215. https://doi.org/10.1002/cncr.30023

5. Korja M, Raj R, Seppa K, Luostarinen T, Malila N, Seppala M, Maenpaa H, Pitkaniemi J (2019) Glioblastoma survival is improving despite increasing incidence rates: a nationwide study between 2000 and 2013 in Finland. Neuro Oncol 21:370-379. https://doi. org/10.1093/neuonc/noy164

6. Jakola AS, Myrmel KS, Kloster R, Torp SH, Lindal S, Unsgård G, Solheim O (2012) Comparison of a strategy favoring early surgical resection vs a strategy favoring watchful waiting in lowgrade gliomas. JAMA 308:1881-1888. https://doi.org/10.1001/ jama.2012.12807

7. Aghi MK, Nahed BV, Sloan AE, Ryken TC, Kalkanis SN, Olson JJ (2015) The role of surgery in the management of patients with diffuse low grade glioma: a systematic review and evidence-based clinical practice guideline. J Neurooncol 125:503530. https://doi.org/10.1007/s11060-015-1867-1

8. Brown TJ, Brennan MC, Li M, Church EW, Brandmeir NJ, Rakszawski KL, Patel AS, Rizk EB, Suki D, Sawaya R (2016) Association of the extent of resection with survival in glioblastoma: a systematic review and meta-analysis. JAMA Oncol 2:1460-1469. https://doi.org/10.1001/jamaoncol.2016.1373

9. Stone P, Richardson A, Ream E, Smith A, Kerr D, Kearney N, Forum CF (2000) Cancer-related fatigue: inevitable, unimportant and untreatable? Results of a multi-centre patient survey. Ann Oncol 11:971-975. https://doi.org/10.1023/a:1008318932 641

10. Struik K, Klein M, Heimans JJ, Gielissen MF, Bleijenberg G, Taphoorn MJ, Reijneveld JC, Postma TJ (2009) Fatigue in lowgrade glioma. J Neurooncol 92:73-78. https://doi.org/10.1007/ s11060-008-9738-7

11. Gustafsson M, Edvardsson T, Ahlstrom G (2006) The relationship between function, quality of life and coping in patients with lowgrade gliomas. Support Care Cancer 14:1205-1212. https://doi. org/10.1007/s00520-006-0080-3

12. Aprile I, Chiesa S, Padua L, Di Blasi C, Arezzo MF, Valentini V, Di Stasio E, Balducci M (2015) Occurrence and predictors of the fatigue in high-grade glioma patients. Neurol Sci 36:1363-1369. https://doi.org/10.1007/s10072-015-2111-7

13. Valko PO, Siddique A, Linsenmeier C, Zaugg K, Held U, Hofer S (2014) Prevalence and predictors of fatigue in glioblastoma: a prospective study. Neuro Oncol 17:274-281. https://doi.org/10.1093/ neuonc/nou 127

14. Cheng J-x, Liu B-1, Zhang X, Lin W, Zhang Y-q, Liu W-p, Zhang J-n, Lin H, Wang R, Yin H (2010) Health-related quality of life in glioma patients in China. BMC Cancer 10:305. https://doi. org/10.1186/1471-2407-10-305 
15. Bower JE (2014) Cancer-related fatigue-mechanisms, risk factors, and treatments. Nat Rev Clin Oncol 11:597-609. https://doi. org/10.1038/nrclinonc.2014.127

16. O'Higgins C, Brady B, O'Connor B, Walsh D, Reilly R (2018) The pathophysiology of cancer-related fatigue: current controversies. Support Care Cancer. https://doi.org/10.1007/s0052 0-018-4318-7

17. Osoba D, Aaronson NK, Muller M, Sneeuw K, Hsu MA, Yung WK, Brada M, Newlands E (1997) Effect of neurological dysfunction on health-related quality of life in patients with high-grade glioma. J Neurooncol 34:263-278. https://doi. org/10.1023/a:1005790632126

18. Yavas C, Zorlu F, Ozyigit G, Gurkaynak M, Yavas G, Yuce D, Cengiz M, Yildiz F, Akyol F (2012) Health-related quality of life in high-grade glioma patients: a prospective single-center study. Support Care Cancer 20:2315-2325. https://doi.org/10.1007/ s00520-011-1340-4

19. Brown PD, Ballman KV, Rummans TA, Maurer MJ, Sloan JA, Boeve BF, Gupta L, Tang-Wai DF, Arusell RM, Clark MM, Buckner JC (2006) Prospective study of quality of life in adults with newly diagnosed high-grade gliomas. J Neurooncol 76:283-291. https://doi.org/10.1007/s11060-005-7020-9

20. Lee EQ, Muzikansky A, Drappatz J, Kesari S, Wong ET, Fadul CE, Reardon DA, Norden AD, Nayak L, Rinne ML, Alexander BM, Arvold ND, Doherty L, Stefanik J, LaFrankie D, Ruland SF, Pulverenti J, Smith KH, Gaffey SC, Hammond S, Wen PY (2016) A randomized, placebo-controlled pilot trial of armodafinil for fatigue in patients with gliomas undergoing radiotherapy. Neuro Oncol 18:849-854. https://doi.org/10.1093/neuonc/now007

21. Molassiotis A, Wilson B, Brunton L, Chaudhary H, Gattamaneni $\mathrm{R}, \mathrm{McBain} \mathrm{C}$ (2010) Symptom experience in patients with primary brain tumours: a longitudinal exploratory study. Eur J Oncol Nurs 14:410-416. https://doi.org/10.1016/j.ejon.2010.03.001

22. Louis DN, Ohgaki H, Wiestler OD, Cavenee WK, Burger PC, Jouvet A, Scheithauer BW, Kleihues P (2007) The 2007 WHO classification of tumours of the central nervous system. Acta Neuropathol 114:97-109. https://doi.org/10.1007/s00401-007-0243-4

23. Aaronson NK, Ahmedzai S, Bergman B, Bullinger M, Cull A, Duez NJ, Filiberti A, Flechtner H, Fleishman SB, de Haes JC (1993) The European Organization for Research and Treatment of Cancer QLQ-C30: a quality-of-life instrument for use in international clinical trials in oncology. JNCI: J Natl Cancer Inst 85:365-376. https://doi.org/10.1093/jnci/85.5.365

24. Charlson ME, Pompei P, Ales KL, MacKenzie CR (1987) A new method of classifying prognostic comorbidity in longitudinal studies: development and validation. J Chronic Dis 40:373-383. https ://doi.org/10.1016/0021-9681(87)90171-8

25. Ibañez FAL, Hem S, Ajler P, Vecchi E, Ciraolo C, Baccanelli M, Tramontano R, Knezevich F, Carrizo A (2011) A new classification of complications in neurosurgery. World Neurosurg 75:709-715. https://doi.org/10.1016/j.wneu.2010.11.010

26. Fayers P, Aaronson NK, Bjordal K, Groenvold M, Curran D, Bottomley A (2001) EORTC QLQ-C30 Scoring Manual (3rd edition). European Organisation for Research and Treatment of Cancer. https://www.eortc.be/qol/files/SCManualQLQ-C30.pdf. Accessed 5 Jan 20192018

27. Giesinger JM, Kuijpers W, Young T, Tomaszewski KA, Friend E, Zabernigg A, Holzner B, Aaronson NK (2016) Thresholds for clinical importance for four key domains of the EORTC QLQC30: physical functioning, emotional functioning, fatigue and pain. Health Qual Life Outcomes 14:87. https://doi.org/10.1186/ s12955-016-0489-4

28. Maringwa J, Quinten C, King M, Ringash J, Osoba D, Coens C, Martinelli F, Reeve BB, Gotay C, Greimel E, Flechtner H, Cleeland CS, Schmucker-Von Koch J, Weis J, Van Den Bent MJ, Stupp R, Taphoorn MJ, Bottomley A (2011) Minimal clinically meaningful differences for the EORTC QLQ-C30 and EORTC QLQ-BN20 scales in brain cancer patients. Ann Oncol 22:21072112. https://doi.org/10.1093/annonc/mdq726

29. Hjermstad MJ, Fayers PM, Bjordal K, Kaasa S (1998) Healthrelated quality of life in the general Norwegian population assessed by the European Organization for Research and Treatment of Cancer Core Quality-of-Life Questionnaire: the QLQ=C30 (+ 3). J Clin Oncol 16:1188-1196. https://doi. org/10.1200/jco.1998.16.3.1188

30. Page BR, Shaw EG, Lu L, Bryant D, Grisell D, Lesser GJ, Monitto DC, Naughton MJ, Rapp SR, Savona SR, Shah S, Case D, Chan MD (2015) Phase II double-blind placebo-controlled randomized study of armodafinil for brain radiation-induced fatigue. Neuro Oncol 17:1393-1401. https://doi.org/10.1093/neuonc/nov084

31. Armstrong TS, Cron SG, Bolanos EV, Gilbert MR, Kang DH (2010) Risk factors for fatigue severity in primary brain tumor patients. Cancer 116:2707-2715. https://doi.org/10.1002/ cncr. 25018

32. Van Wijk CMG, Kolk AM (1997) Sex differences in physical symptoms: the contribution of symptom perception theory. Soc Sci Med 45:231-246. https://doi.org/10.1016/s0277 -9536(96)00340-1

33. Westbrook MT, Viney LL (1983) Age and sex differences in patients' reactions to illness. J Health Soc Behav. https://doi. org/10.2307/2136398

34. Pater JL, Zee B, Palmer M, Johnston D, Osoba D (1997) Fatigue in patients with cancer: results with National Cancer Institute of Canada Clinical Trials Group studies employing the EORTC QLQ-C30. Support Care Cancer 5:410-413

35. Helseth R, Helseth E, Johannesen T, Langberg C, Lote K, Rønning P, Scheie D, Vik A, Meling T (2010) Overall survival, prognostic factors, and repeated surgery in a consecutive series of 516 patients with glioblastoma multiforme. Acta Neurol Scand 122:159-167

36. Weller M, Van Den Bent M, Tonn JC, Stupp R, Preusser M, Cohen-Jonathan-Moyal E, Henriksson R, Le Rhun E, Balana C, Chinot O (2017) European Association for Neuro-Oncology (EANO) guideline on the diagnosis and treatment of adult astrocytic and oligodendroglial gliomas. Lancet Oncol 18:315-329

37. Drewes C, Sagberg LM, Jakola AS, Solheim O (2018) Perioperative and postoperative quality of life in patients with glioma-a longitudinal cohort study. World Neurosurg 117:e465-e474. https ://doi.org/10.1016/j.wneu.2018.06.052

38. van Breemen MS, Wilms EB, Vecht CJ (2007) Epilepsy in patients with brain tumours: epidemiology, mechanisms, and management. Lancet Neurol 6:421-430

39. Knobel H, Loge JH, Brenne E, Fayers P, Hjermstad MJ, Kaasa S (2003) The validity of EORTC QLQ-C30 fatigue scale in advanced cancer patients and cancer survivors. Palliat Med 17:664-672. https://doi.org/10.1191/0269216303pm841oa

40. Walker M, Brown J, Brown K, Gregor A, Whittle I, Grant R (2003) Practical problems with the collection and interpretation of serial quality of life assessments in patients with malignant glioma. J Neurooncol 63:179-186. https://doi.org/10.1023/a:10239 00802254

41. Dirven L, Reijneveld JC, Aaronson NK, Bottomley A, Uitdehaag BM, Taphoorn MJ (2013) Health-related quality of life in patients with brain tumors: limitations and additional outcome measures. Curr Neurol Neurosci Rep 13:359. https://doi.org/10.1007/s1191 0-013-0359-y

42. Stupp R, Mason WP, Van Den Bent MJ, Weller M, Fisher B, Taphoorn MJ, Belanger K, Brandes AA, Marosi C, Bogdahn U (2005) Radiotherapy plus concomitant and adjuvant temozolomide for glioblastoma. N Engl J Med 352:987-996. https://doi. org/10.1056/NEJMoa043330 
43. Buckner JC, Shaw EG, Pugh SL, Chakravarti A, Gilbert MR, Barger GR, Coons S, Ricci P, Bullard D, Brown PD, Stelzer K, Brachman D, Suh JH, Schultz CJ, Bahary JP, Fisher BJ, Kim H, Murtha AD, Bell EH, Won M, Mehta MP, Curran WJ Jr (2016) Radiation plus procarbazine, $\mathrm{CCNU}$, and vincristine in low-grade glioma. N Engl J Med 374:1344-1355. https://doi.org/10.1056/ NEJMoa1500925

44. Dirven L, Aaronson NK, Heimans JJ, Taphoorn MJ (2014) Health-related quality of life in high-grade glioma patients. Chin J Cancer 33:40-45. https://doi.org/10.5732/cjc.013.10214
45. Halkett GK, Lobb EA, Oldham L, Nowak AK (2010) The information and support needs of patients diagnosed with high grade glioma. Patient Educ Couns 79:112-119

Publisher's Note Springer Nature remains neutral with regard to jurisdictional claims in published maps and institutional affiliations. 